\author{
Part of Journal of Research of the National Bureau of Standards, Volume 35, \\ October 1945
}

\title{
COMPRESSION OF SOLE LEATHER
}

\author{
By Charles E. Weir
}

ABSTRACT

Specimens of sole leather were subjected to indentation tests and compressive tests. Comparisons between compression data and the indentation numbers of the original dry leather show that compression may be used as a measure of indentation. Compression of dry leather gives results showing better correlation between the methods and eliminates distortions occurring when moist leather is compressed. Compression data show satisfactory reproducibility. Compression for a three-minute period is adequate for test purposes, all changes being completed in this interval with the exception of a very minute compression proceeding at a slow rate. Compensation for variations in thickness of specimens may be effected by expressing the results in terms of percentage compression. Area and shape of specimens do not affect the compression appreciably. Compression-decompression curves show large hysteresis loops. The effect of tannery rolling in compressing leather is estimated to be equivalent to that produced by pressures of from 2,000 to $3,000 \mathrm{lb} / \mathrm{in}^{2}$. Based upon the data obtained in the compressive tests, the lower limit of the coefficient of compressibility of leather is estimated to be $33 \times 10^{-6} \mathrm{bar}^{-1}$.

\section{CONTENTS}

I. Introduction

II. Instruments for measuring indentation and compression

1. ASTM rubber hardness tester

2. McBurney indentation tester

3. Sigler indentation tester

4. Hydraulic press

5. Hydraulic testing machine

6. Thickness gage

III. Preparation of specimens and experimental procedure

1. Indentation of dry leather and compression of moist leather

2. Indentation and compression of dry leather

3. Stress-strain measurements

IV. Results and discussion

1. Compression of moist specimens

2. Compression of dry specimens

3. Reproducibility of compression data

4. Effect of duration of the pressure

5. Effect of thickness of the specimen

6. Effect of area and shape of the specimen

7. Stress-strain curves for leather

8. Estimation of tannery rolling pressures

V. Conclusion

VI. References 


\section{INTRODUCTION}

This investigation was undertaken to obtain information on the compressive characteristics of commercial sole leather and to determine the correlation existing between the results of compressive tests and the results of the usual types of indentation tests.

The resistance of sole leather to indentation may be determined by forcing a spherical or a plane circular indenter into the surface of the sample. The depth of penetration under a given load or the increase in depth of penetration produced by an increment of load is taken as the measure of the indentation. Such methods are satisfactory if the material being tested is homogeneous, but are of dubious value for materials that are not uniform. Leather is not homogeneous. It exhibits numerous surface irregularities, and the results of indentation measurements may show a wide variation at neighboring points on a leather specimen. In order to minimize this variation, a method was developed in which a slab of sole leather is subjected to pressure between plane metal plates. This method is described in Federal Specification for Leather and Leather Products, General Specifications, KK-L-311.

Recent studies at this Bureau have shown that additional compression of sole leather improves the wearing quality [1]. ${ }^{1}$ Conabere [2] concluded that the greater the resistance of sole leather to indentation, the better the wear resistance. As additional compression increases the resistance of sole leather both to further compression and also to indentation, the two methods appear to measure closely related properties of leather that are associated with the ability to resist wear.

In this study the change in thickness resulting from compression of sole leather was compared with the indentation results obtained with each of three indentation instruments. Factors that might influence compression, such as thickness, area, and shape of the specimen, were also investigated.

\section{INSTRUMENTS FOR MEASURING INDENTATION AND COMPRESSION}

\section{ASTM RUBBER HARDNESS TESTER}

The ASTM rubber hardness tester [3] consists essentially of an indenting rod, $3 / 32$ in. in diameter, which protrudes through a flat presser foot. The indenter, which has a hemispherical indenting surface with a radius of curvature of $3 / 64$ in. actuates a dial micrometer that indicates the depth of penetration of the rod. In these tests a load of $5 \mathrm{lb}$ was applied to the indenter.

The indentation number is the difference in reading of the dial micrometer, expressed in thousandths of an inch, between the value indicated when the instrument is placed on a plane glass surface and the value indicated when it is placed on the specimen.

\section{MCBURNEY INDENTATION TESTER}

The McBurney instrument [4] consists of an indenting rod, $1 / 4 \mathrm{in}$. in diameter, which protrudes through a flat presser foot. The indenter,

\footnotetext{
1 Figures in brackets indicate the literature references at the end of this paper.
} 
which has a hemispherical indenting surface with a radius of curvature of $1 / 8$ in., actuates a dial micrometer that indicates the depth of penetration of the rod. The zero setting of the dial micrometer is obtained on the specimen under test with a load of $2 \mathrm{lb}$ on the indenter.

The indentation number is the difference in the reading of the dial micrometer, expressed in thousandths of an inch, between the value indicated when a load of $2 \mathrm{lb}$ is applied to the indenter and the value indicated when a load of $30 \mathrm{lb}$ is applied to the indenter.

\section{SIGLER INDENTATION TESTER}

The Sigler indentation instrument [5] differs from the instruments previously described in that it uses interchangeable flat-surfaced indenters that may be loaded as desired. In these tests a load of $180 \mathrm{lb}$ was applied to plane-ended rod, $1 / 8$ in. in diameter. As the dial micrometer which indicates the position of the indenter is adjusted to read zero when the indenter is in contact with the base plate, it is necessary to measure the thickness of the specimen independently to obtain a value for indentation. This measurement was made with a dial micrometer instrument, which carried a load of $1 / 4 \mathrm{lb}$ on a presser foot $1 / 8$ in. in diameter.

The indentation number is the difference, in thousandths of an inch, between the thickness of the specimen and the reading of the dial micrometer of the indentation instrument at the conclusion of the indentation period.

\section{HYDRAULIC PRESS}

Loads were applied to the plane platens, between which the samples were loaded during the compression tests by means of a hydraulic jack operated by a motor-driven pump. The capacity of the press was 50 tons. Loads were indicated by a Bourdon tube gage.

\section{HYDRAULIC TESTING MACHINE}

A 30-ton capacity hydraulic testing machine was used to obtain stress-strain measurements. The load was applied by means of a hydraulic jack operated by a motor-driven pump and was indicated by a pointer that moved around a graduated circular scale.

The compression was measured by means of two dial micrometers, which indicated the movement of one circular compression platen with respect to the other. The two dial micrometers were located at the opposite ends of a diameter of the platens. The compression was considered to be the average of the compressions indicated by the two micrometers.

Stress-strain measurements were made at a rate of loading of 10,000 $\mathrm{lb} / \mathrm{min}$.

\section{THICKNESS GAGE}

A dial micrometer was used for measurements of thickness of specimens before and after compression. A load of $450 \mathrm{~g}$ was applied to a plane presser foot $3 / 8$ in. in diameter. 


\section{PREPARATION OF SPECIMENS AND EXPERIMENTAL PROCEDURE}

\section{INDENTATION OF DRY LEATHER AND COMPRESSION OF MOIST LEATHER}

Specimens of sole leather were cut to a size of 2 by $4 \mathrm{in}$. by means of a steel die, and were conditioned at $72^{\circ} \mathrm{F}$ and 65 -percent relative humidity for $72 \mathrm{hr}$. The indentation numbers of each specimen were determined on the Sigler indentation tester at eight points, i. e., two rows of four points, each $3 / 4$ in. from the longer edge and spaced approximately $3 / 4$ in. apart. The average of these eight measurements was considered to be the indentation number of the specimen.

The thickness of each specimen was measured at eight marked points, and the average of these measurements was taken as the thickness of the specimen. Each specimen was weighed and then immersed in water until 10 percent \pm 1 percent by weight of water was absorbed. The moist specimen was conditioned at $72^{\circ} \mathrm{F}$ and 100-percent relative humidity for $48 \mathrm{hr}$, compressed for $3 \mathrm{~min}$ at a pressure of $3,000 \mathrm{lb} / \mathrm{in}^{2}$ and dried at $72^{\circ} \mathrm{F}$ and 65 -percent relative humidity. The thickness of the dry specimen was redetermined at the marked points and the average taken. The difference between the original and the final thickness was considered to be the compression.

\section{INDENTATION AND COMPRESSION OF DRY LEATHER}

The dry specimens for compressive tests were prepared in a similar manner and conditioned at $72^{\circ} \mathrm{F}$ and 65 -percent relative humidity. The indentation numbers of each specimen were determined on the ASTM instrument at eight points, spaced as previously described, and on the Sigler indentation tester at eight points adjacent to the points used for the measurements on the ASTM gage. The indentation was then determined on the McBurney instrument at four points, spaced $3 / 4$ in. apart on the longer center line of the specimen. All indentation measurements were made $30 \mathrm{sec}$ after application of the load. The averages of the measurements with each instrument were taken as the indentation numbers of the specimen.

The thickness of each specimen was measured at eight marked points, and the average was taken as the thickness of the specimen. Each specimen was compressed for 3 min at a pressure of $3,000 \mathrm{lb} / \mathrm{in} .{ }^{2}$, and the load was removed. The thickness was redetermined immediately at the marked points. The specimens were conditioned for $24 \mathrm{hr}$ at $72^{\circ} \mathrm{F}$ and 65 -percent relative humidity, and the thickness was redetermined. The thickness of some specimens was measured for the third time at the conclusion of 30 days.

\section{STRESS-STRAIN MEASUREMENTS}

For stress-strain measurements, 2- by 4 -in. specimens were halved with a band saw to give 2-by 2 -in. blocks; and the irregularities of the edge, caused by the die and the saw, were removed by buffing. This treatment gave specimens that were uniform in area and that had approximately vertical edges. One-inch blocks were cut by a band saw and buffed, and disks having approximately vertical edges were 
cut by a circular die. These specimens were conditioned for $24 \mathrm{hr}$ at $77^{\circ} \mathrm{F}$ and 50-percent relative humidity. The area of each specimen was measured with a planimeter. The measurements made on these specimens were varied and will be described subsequently.

\section{RESULTS AND DISCUSSION}

\section{COMPRESSION OF MOIST SPECIMENS}

The results of the compression of the moist specimens are shown in figure 1 , where the change in thickness resulting from compression is plotted as the ordinate and the Sigler indentation number as the abscissa. The figure shows that, although there appears to be some relationship between the indentation of leather when dry and the compression when moist, the relationship is not well defined.

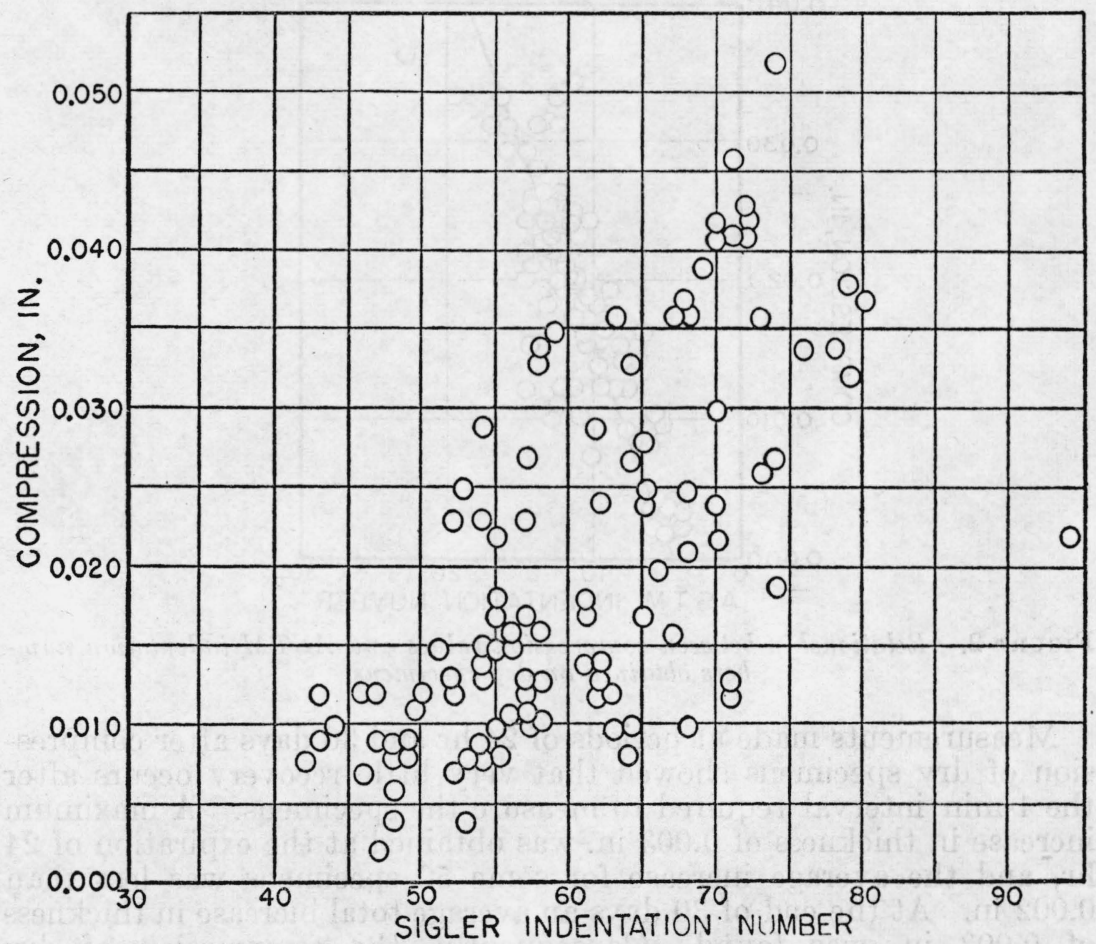

FIGURE 1.-Relationship between compression values for moist leather and Sigler indentation numbers obtained on the same specimens in a dry condition.

Two objectionable features were connected with the compression of moist leather. During the compression, water soluble material was squeezed from the leather, and the resulting specimen was probably chemically different from the original leather. After compression most specimens were warped and could not be measured accurately. Apparently, the grain layer undergoes more lateral expansion than the flesh layer under pressure, as the specimen is invariably convex as viewed from the grain surface. Neither of these objections is manifest when dry leather is compressed. 


\section{COMPRESSION OF DRY SPECIMENS}

Comparisons between the results of compression of dry leather and the results of indentation are shown in figures 2,3 , and 4 , where the compressions are plotted as ordinates and the indentation numbers as abscissas. All three figures contain an equal number of points representing data obtained on the same specimens. The lines were fitted to the points by inspection. No attempt was made to differentiate between various leathers. Every available type of vegetabletanned sole leather, irrespective of origin, tannage, thickness, or location, was tested; and all the results are shown in the figures. The points in the lower left portion of each figure, which represent leather much harder than is available commercially, were obtained by subjecting some specimens to compression before testing.

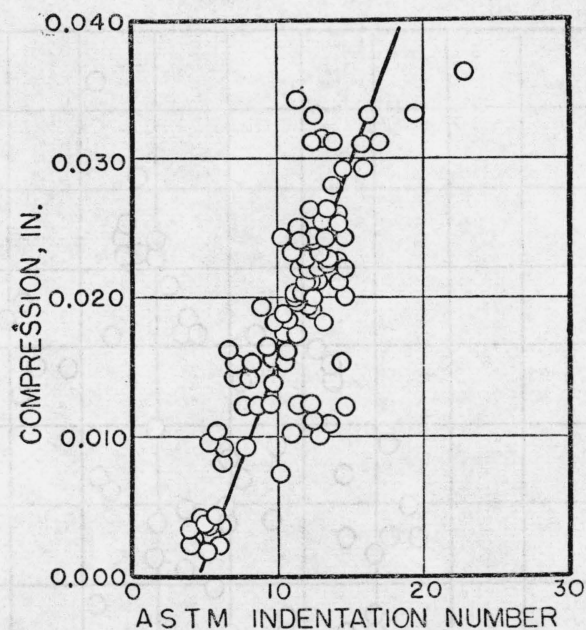

FIGURE 2.-Relationship between compression values and ASTM indentation numbers obtained on dry specimens.

Measurements made at periods of $24 \mathrm{hr}$ and 30 days after compression of dry specimens showed that very little recovery occurs after the 1-min interval required to measure the specimens. A maximum increase in thickness of 0.003 in. was obtained at the expiration of 24 $\mathrm{hr}$, and the average increase for some 50 specimens was less than 0.002 in. At the end of 30 days an average total increase in thickness of 0.003 in. was found. Consequently, the compression of dry leather gives a product that appears to be stable and, for testing purposes, is not too sensitive to the time factor.

The results show that correlation between the data obtained by compression of dry leather and the Sigler indentation numbers is better than that with the ASTM and McBurney numbers. Considering the compression as the dependent variable, the standard errors of the points from the lines are $0.006,0.005$, and 0.002 in., respectively, in figures 2,3 , and 4 . A consideration of the mechanisms by which indentation occurs leads to the conclusion that this is to be expected. The Sigler instrument and the press compress the specimens between plane surfaces, whereas the ASTM and McBurney testers use hemi- 
spherical indenters. Furthermore, the loads on the Olsen and McBurney indenters are so small that surface irregularities may have a significant influence on the indentation numbers obtained with these instruments.

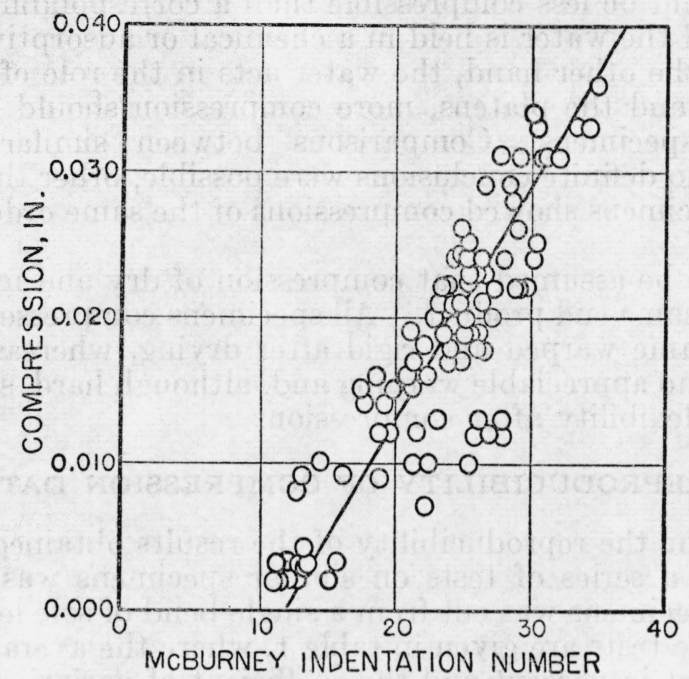

FIGURE 3.-Relationship between compression values and McBurney indentation numbers obtained on dry specimens.

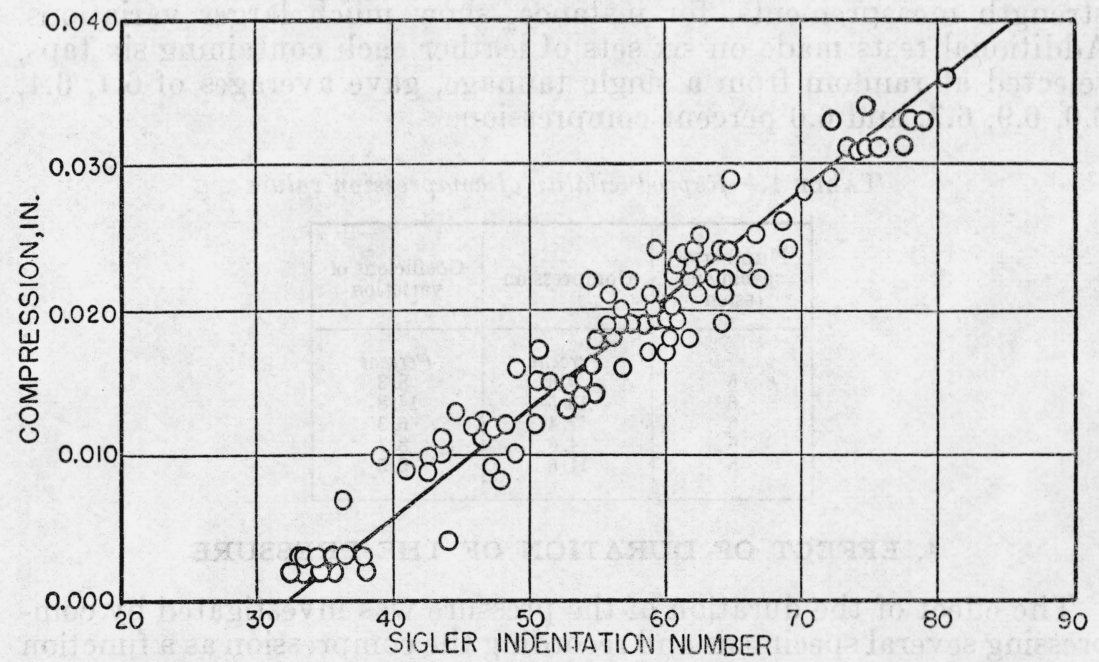

FIGURE 4.-Relationship between compression values and Sigler indentation numbers obtained on dry specimens.

Comparison of figures 1 and 4 shows that better agreement exists when dry, rather than moist, leather is compressed. As in one case both compression and indentation measurements were made on dry leather, and in the other case indentation measurements were made on dry leather and compression measurements on moist leather, this is 


\section{Journal of Research of the National Bureau of Standards}

not surprising. The amount of water in the moist leather cannot be accurately controlled and the effect of the water on the structure of the leather is probably complex. If the voids in the specimen are filled with a relatively incompressible liquid such as water, the moist specimen should be less compressible than a corresponding dry specimen, provided the water is held in a chemical or adsorptive combination. If, on the other hand, the water acts in the role of a lubricant for the fibers and the platens, more compression should be obtained with moist specimens. Comparisons between similar specimens showed that no definite conclusions were possible, other than that dry and moist specimens showed compressions of the same order of magnitude.

It must not be assumed that compression of dry and moist leather results in the same end product. All specimens compressed in a moist condition became warped and rigid after drying, whereas dry specimens showed no appreciable warping and, although hard, still retained considerable flexibility after compression.

\section{REPRODUCIBILITY OF COMPRESSION DATA}

To determine the reproducibility of the results obtained from compressive tests a series of tests on similar specimens was performed. Each set of specimens was cut from a single bend of sole leather. The results of these tests are given in table 1 , where the average compression of each set in percent and the coefficient of variation within the set are given. The variations shown are small in comparison with variations known to occur in other measurements on leather. Tensilestrength measurements, for instance, show much larger variations. Additional tests made on six sets of leather each containing six taps, selected at random from a single tannage, gave averages of $6.1,6.4$, $6.0,6.9,6.7$, and 6.0 percent compression.

TABLE 1.-Reproducibility.of compression v
\begin{tabular}{|c|c|c|}
\hline $\begin{array}{c}\text { Number of } \\
\text { specimens } \\
\text { tested }\end{array}$ & Compression & $\begin{array}{c}\text { Coefficient of } \\
\text { variation }\end{array}$ \\
\hline & Percent & Percent \\
6 & 9.6 & 8.3 \\
6 & 13.5 & 14.8 \\
6 & 17.4 & 6.3 \\
6 & 4.6 & 8.7 \\
6 & 11.6 & 9.5 \\
\hline
\end{tabular}

\section{EFFECT OF DURATION OF THE PRESSURE}

The effect of the duration of the pressure was investigated by compressing several specimens and recording the compression as a function of the time. To simulate the previous compressions, the pressure was applied as rapidly as possible, and then maintained for the duration of the test. The load was applied at the rate of $60,000 \mathrm{lb} / \mathrm{min}$, and, after the desired load was reached, was held constant to within $\pm 50 \mathrm{lb}$.

Two typical curves are shown in figure 5 , in which the percentage compression is plotted as a function of time. These curves show that compression has practically ceased at the conclusion of $3 \mathrm{~min}$. This 
length of time seems suitable for purposes of testing and was used in the previous experiments. The experimental irregularities shown are ascribed to the fact that the thickness measurements were obtained only to the nearest 0.001 in. Although the curves appear flat after the 3-min period, such is not the case. At the end of the longest period of pressure a very slow compression was observed to be proceeding.

\section{EFFECT OF THICKNESS OF THE SPECIMEN}

The thickness of the specimen has a decided effect on the compression. The effect of thickness was not discussed in connection with figures 2,3 , and 4 because the specimens did not differ appreciably in

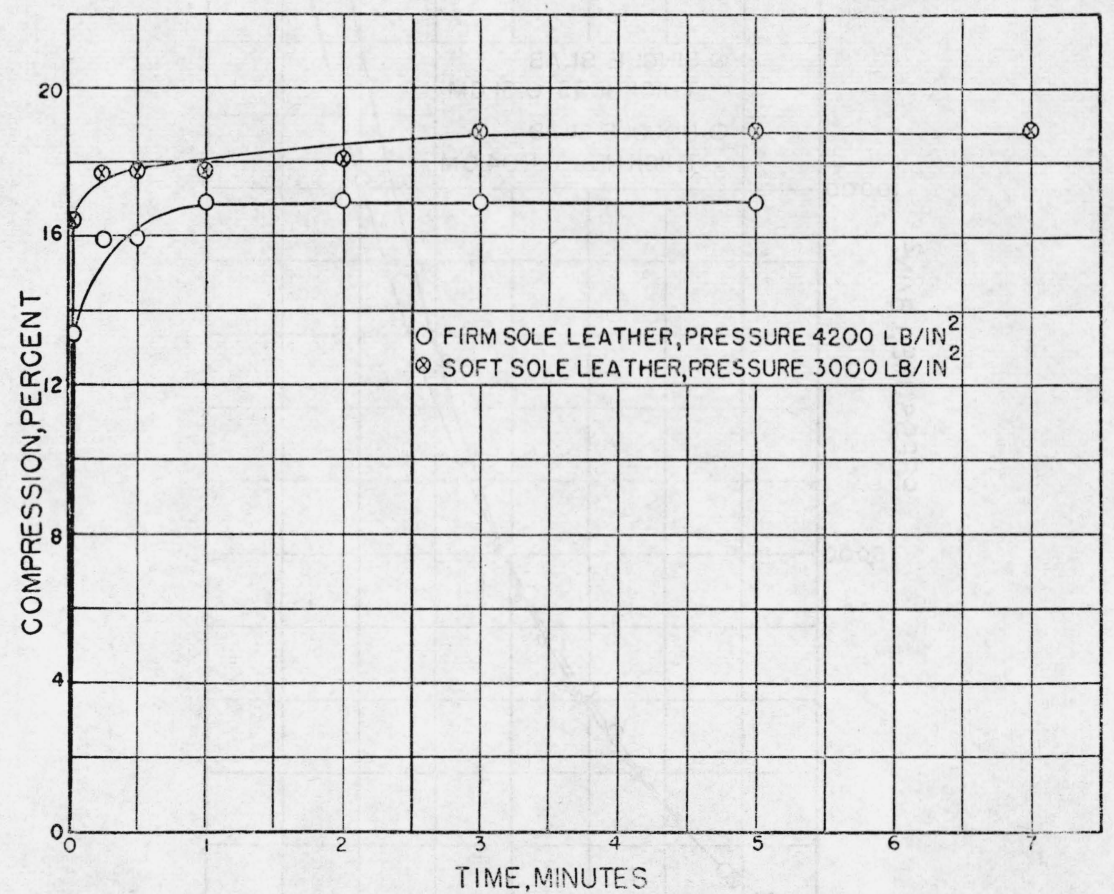

FIGURE 5.-Effect of duration of compression.

thickness, and the small variations which occurred should affect measurements of compression and indentation in essentially the same manner and tend to compensate. To compare the results of compression of different specimens, however, the thicknesses must be considered. The use of percentage compression, i. e., the change in thickness divided by the original thickness of the specimen multiplied by 100 , gives results that agree when the thickness varies in a $2: 1$ ratio as shown by figures 6 and 7 . Figure 6 shows the stress-strain diagrams obtained with a single block of leather and a block of double thickness, formed by placing two similar blocks together, flesh to grain. The curves in figure 7 were obtained with a normal block of leather and a thin block, formed by buffing the flesh surface of a similar block. The 
compression values indicated by the curves agree within 3 percent compression at $3,000 \mathrm{lb} / \mathrm{in}^{2}$.

\section{EFFECT OF AREA AND SHAPE OF THE SPECIMEN}

The area and shape of the specimen used for compressive tests have little effect on the compression value, as is shown in figure 8. This figure shows pressure-compression diagrams for two sizes of square

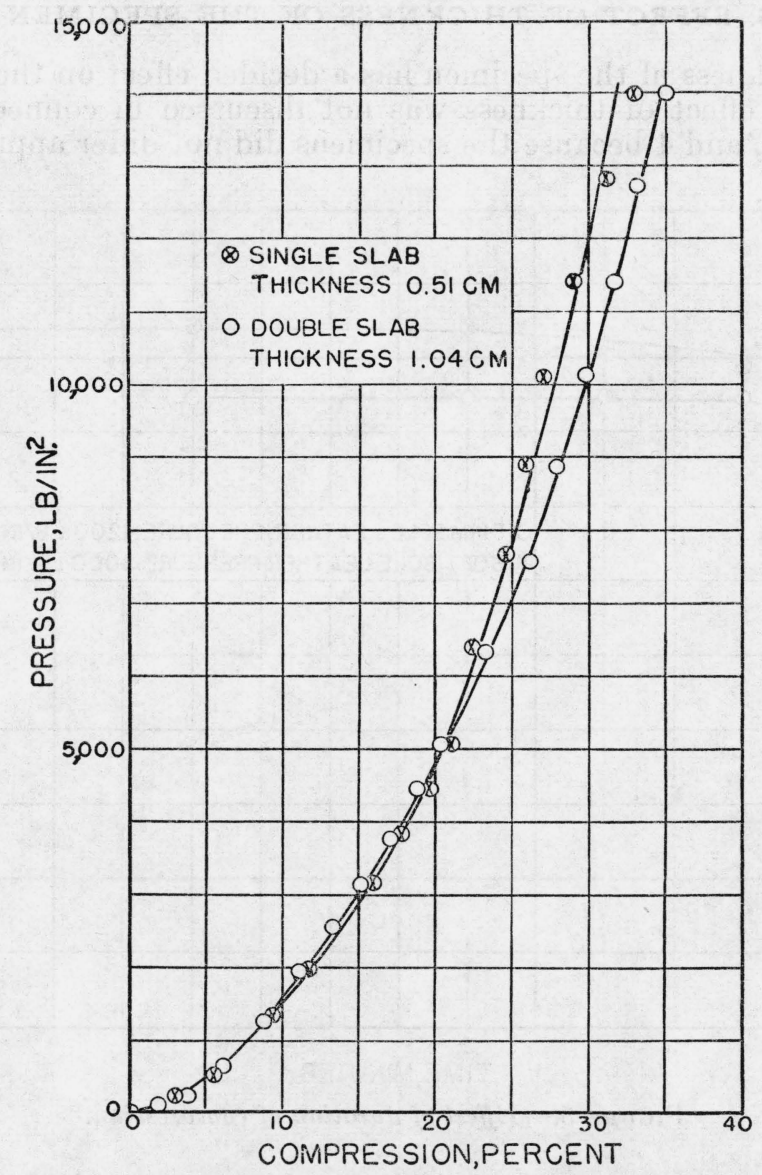

FIGURE 6.-Effect of thickness of specimen on compression; slab of normal thickness and slab of double thickness.

slabs and disks of the same leather. The results for the slabs and the larger disk are in excellent agreement, whereas the results for the smaller disk show a deviation of the order of 5 percent compression. This deviation may be due to variation of the leather, or may be experimental in nature. The area and shape of the specimen may be chosen to give a convenient load, although in order to reduce the effect of variation, it is desirable to test a large specimen.

It is to be noted that the structure of leather breaks down at a pressure of approximately $35,000 \mathrm{lb} / \mathrm{in}^{2}$. This failure is indicated by 
the broken lines shown in figure 8. At this pressure the specimens spread laterally under the vertical pressure in spite of the concentric grooves in the platens designed to resist lateral motion.

\section{STRESS-STRAIN CURVES FOR LEATHER}

Stress-strain diagrams for rolled and unrolled sole leather are shown in figure 9. The compression and decompression portions of the curves are denoted by arrows.

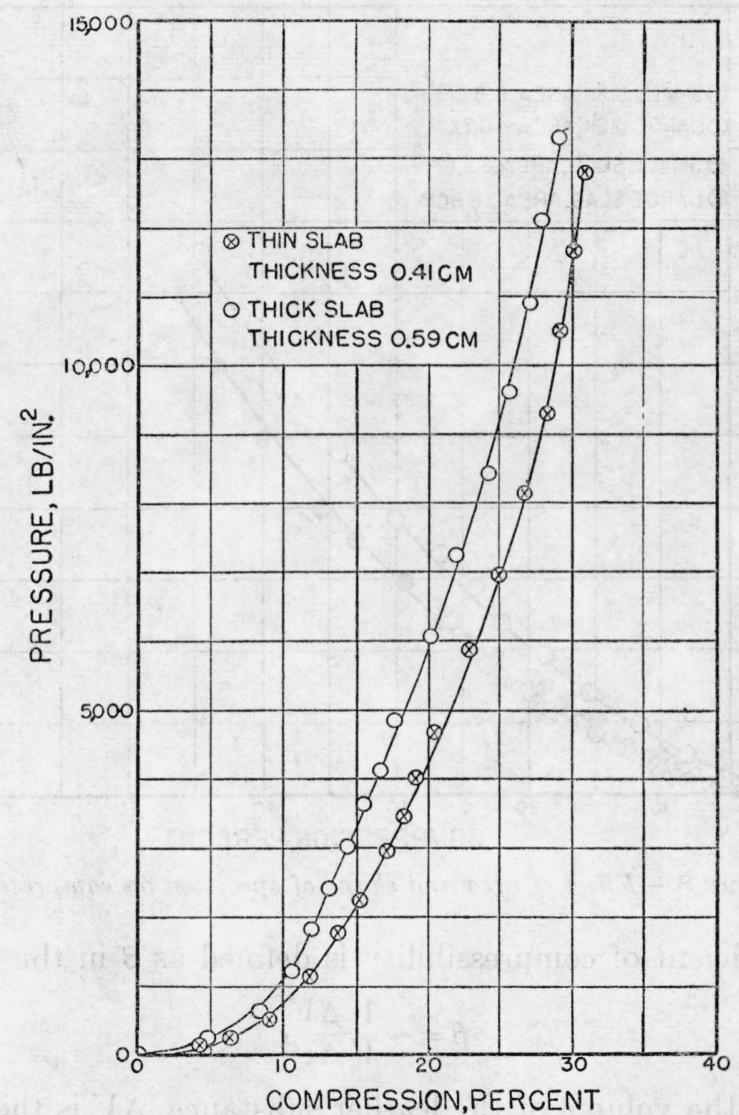

FigURe 7.-Effect of thickness of specimen on compression; normal slab and thin slab.

The compression of leather consists in two main processes. First, a packing of the fibers resulting in the elimination of the interstitial voids; and second, the compression of the leather substance. As it is improbable that the voids can be completely eliminated, both processes probably occur simultaneously at all except the lowest pressures. When the pressure on the compressed specimen is reduced, the resultant decompression curve does not follow the compression curve, as shown by the large hysteresis loops in figure 9 .

Reduction of pressure should result predominately in an expansion of the compressed leather substance until the pressure reaches a value 
at which the fibers are able to separate. A linear relationship between pressure and percentage compression does not hold after this point is reached. This point occurs at a pressure of approximately 3,500 $\mathrm{lb} / \mathrm{in}^{2}$ in the curves shown in figure 9 . The slopes of the linear portions of the decompression curves were found to be nearly the same for a wide variety of specimens. This indicates that the principal process occurring in this region of pressure is an expansion of the leather substance.

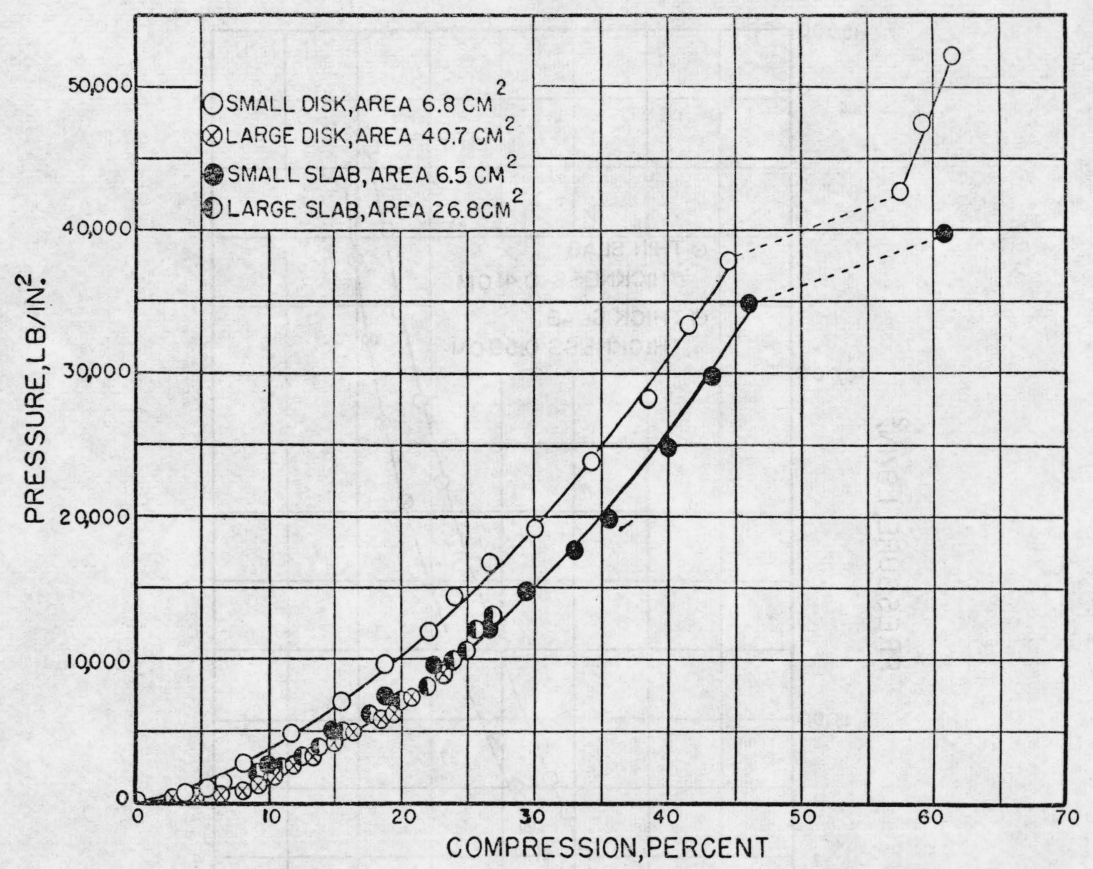

FIGURE 8.-Effect of area and shape of specimen on compression.

The coefficient of compressibility is defined as $\beta$ in the equation

$$
\beta=-\frac{1}{V} \frac{\Delta V}{\Delta P},
$$

where $V$ is the volume of the leather substance, $\Delta V$ is the change in this volume, and $\Delta P$ is the change in pressure. The pressure defined by eq 1 is a force per unit area acting in all directions and may be realized experimentally only by fluid pressure.

The ratio of the length of the shortest side to the thickness of the specimen in these tests was at least 8:1. Measurements of the areas of specimens after compression indicated that any increase in area was less than the experimental accuracy of the area measurement and probably an effect of the second order. Errors resulting from the application of eq 1 to leather under vertical pressure will most probably result in too low a value for $\Delta V$.

The true volume of the leather fibers, exclusive of void space, is not known. Measurements by J. R. Kanagy and E. L. Wallace [6] have 
shown that the dimensional volume is in error by at least 20 percent after compressing leather at a pressure of $3,000 \mathrm{lb} / \mathrm{in}^{2}$

Use of the observed volume change and the dimensional volume in eq 1 will, therefore, lead to an estimate of the lower limit of the coefficient of compressibility of leather. The average value for this limit was found to be $33 \times 10^{-6} \mathrm{bar}^{-1}$.

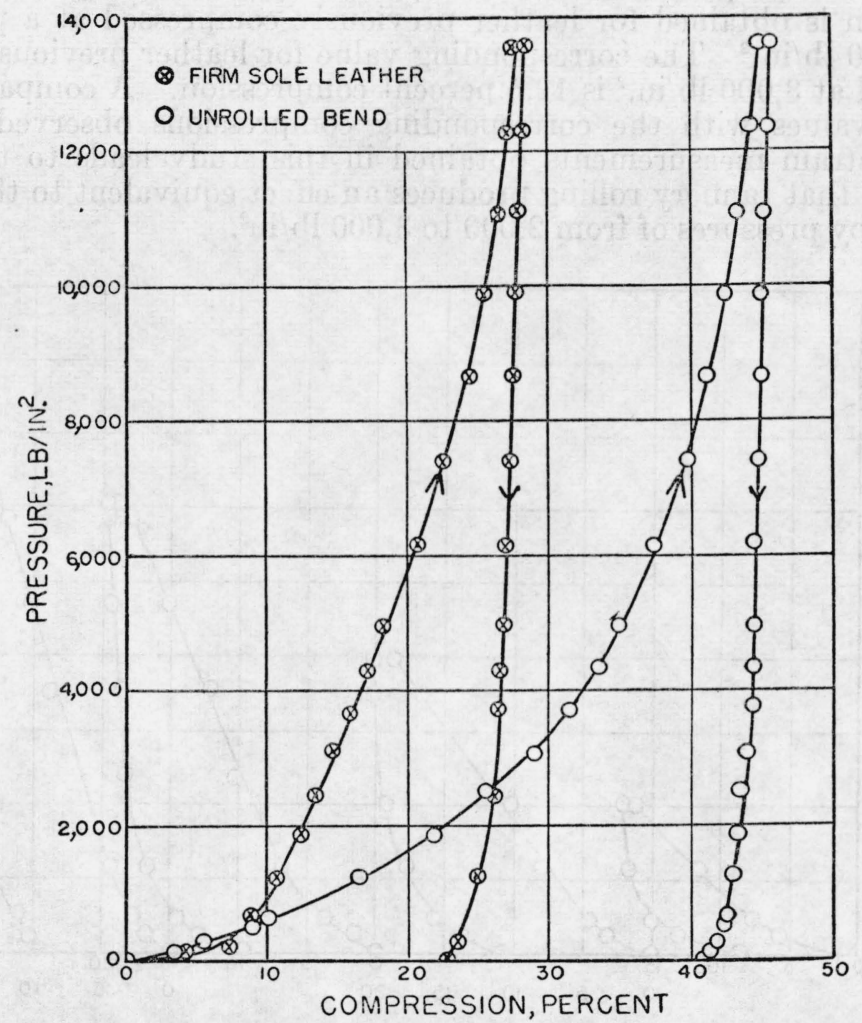

FigURe 9.-Compression-decompression curves for leather.

\section{ESTIMATION OF TANNERY ROLLING PRESSURES}

The choice of the pressure of $3,000 \mathrm{lb} / \mathrm{in}^{2}$ for purposes of testing was arbitrary. This pressure was considered to be available on ordinary presses with a specimen at least 4 in. $^{2}$ in area. Although higher pressures produce larger compressions, a pressure of $3,000 \mathrm{lb} / \mathrm{in}^{2}{ }^{2}$ is adequate to produce measurable compressions of all commercial leather tested, and even of leather that had been compressed before testing, as shown in figures 2,3 , and 4 .

The pressure exerted on the leather during the rolling operation at the tannery cannot be evaluated readily, yet it is of considerable interest. In order to estimate this pressure, a specimen of unrolled leather taken from the bend location of the hide was compressed consecutively to pressures of $1,000,2,000,3,000$, and 4,000 lb/in. ${ }^{2}$, and the stress-strain diagrams were drawn. These curves are shown in 
figure 10 , in which each curve has been displaced to reduce confusion of the points.

Comparison of the percentage compression at a given pressure shows that the magnitude of the compression is a measure of the compressive history of the leather. At $1,000 \mathrm{lb} / \mathrm{in}^{2}{ }^{2}$, for instance, the percentage compressions stand in the ratios of $16: 11: 9: 6$ in the four curves. At a pressure of $3,000 \mathrm{lb} / \mathrm{in}^{2}{ }^{2}$ a value of 18.5 percent compression is obtained for leather previously compressed at a pressure of $2,0.00 \mathrm{lb} / \mathrm{in}^{2}{ }^{2}$ The corresponding value for leather previously compressed at $3,000 \mathrm{lb} / \mathrm{in}^{2}$ is 12.5 percent compression. A comparison of these values with the corresponding compressions observed on all stress-strain measurements obtained in this study leads to the conclusion that tannery rolling produces an effect equivalent to that produced by pressures of from 2,000 to $3,000 \mathrm{lb} / \mathrm{in}^{2}$.

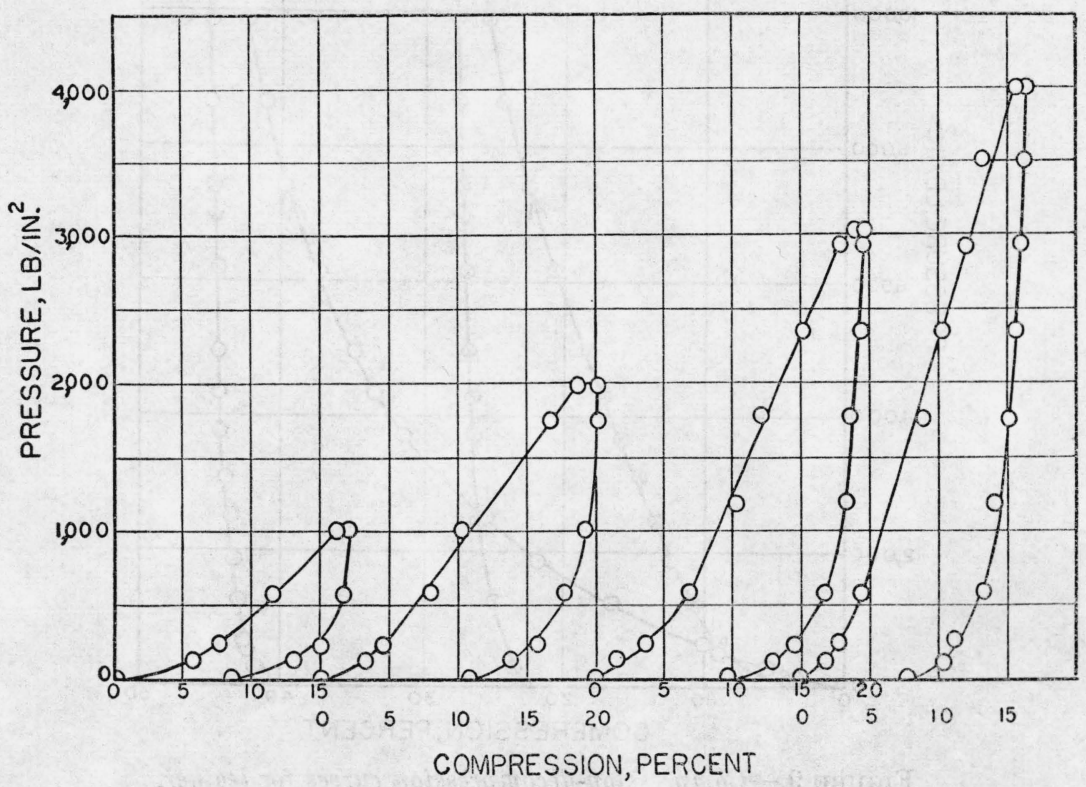

FIGURE 10.-Effect of successive compressions on stress-strain curve.

\section{CONCLUSION}

Comparisons between compressions resulting when sole leather is subjected to a pressure of $3,000 \mathrm{lb} / \mathrm{in}^{2}$ and the indentation numbers of the original leather indicate that compression and indentation measure related properties of leather. To obtain best correlation between these methods, leather should be compressed in the dry state. A compression period of $3 \mathrm{~min}$ is adequate. The thickness, area, and shape of specimens have small effect on results of compression if results are expressed as percentage compression, although it is advisable to use specimens at least 4 in. ${ }^{2}$ in area to reduce the effect of possible variations within the specimen. The effect of tannery rolling in compressing leather is estimated to be equivalent to that produced 
by pressures of from 2,000 to $3,000 \mathrm{lb} / \mathrm{in} .^{2}$. Based upon the data obtained in the compressive tests, the lower limit of the coefficient of compressibility of leather is estimated to be $33 \times 10^{-1} \mathrm{bar}^{-6}$.

\section{REFERENCES}

[1] R. B. Hobbs and R. Kronstadt, Wearing quality of some vegetable-tanned sole leathers, J. Research NBS 34, 33 (1945) RP1626.

[2] G. O. Conabere, Firmness, compressibility and abrasion resistance of sole leather, J. Int. Soc. Leather Trades' Chem. 28, 25 (1944).

[3] Standard Method of Testing Hardness of Rubber, Am. Soc. Testing Materials, Standards, Pt. III, Nonmetallic Materials, p. 597 (1944) D314-39.

[4] J. W. McBurney, Indentation of asphalt tile, Proc. Am. Soc. Testing Materials $\mathbf{3 4}_{2}, 591$ (1934).

[5] P. A. Sigler and Myrtle B. Woodward, Indentation and recovery of low-cost floor coverings, NBS Building Materials and Structures Report BMS14. (1939).

[6] J. R. Kanagy and E. L. Wallace, The density of leather and its significance, J. Am. Leather Chem. Assn. 38, 314 (1943).

Washington, April 19, 1945. 